\title{
Voltammetric Oxidation of Dipyridamole in Aqueous Acid Solutions
}

\author{
Marilza Castilho, Luiz E. Almeida, Marcel Tabak and Luiz H. Mazo* \\ Instituto de Química de São Carlos, Universidade de São Paulo, CP 780, 13560-970, São Carlos - SP, Brazil
}

\begin{abstract}
A oxidação eletroquímica do dipiridamol (DIP) foi estudada em soluções aquosas acidificadas, empregando-se as técnicas de voltametria cíclica e eletrólise a potencial controlado com eletrodos de platina. Os experimentos de eletrólise foram monitorados por voltametria cíclica com ultramicroeletrodo de platina, espectroscopia de absorção óptica e fluorescência, e a integração da corrente durante a eletrólise resultou em uma carga correspondente a 2 elétrons por molécula de DIP. Os voltamogramas cíclicos registrados para o DIP a baixas velocidades de varredura se caracterizam por um único pico de oxidação em processo controlado por difusão, com o aparecimento do pico de redução correspondente a velocidades de varredura maiores que $1 \mathrm{~V} \mathrm{~s}^{-1}$. A estequiometria da reação de oxidação obtida a partir de curvas de polarização de estado estacionário resultou em ordens de reação unitária em relação ao DIP e íons $\mathrm{H}^{+}$.
\end{abstract}

The electrochemical oxidation of dipyridamole (DIP) has been studied in acidified aqueous solutions at platinum electrodes employing cyclic voltammetry and controlled-potential electrolysis. The progress of the anodic oxidation as a function of time was monitored by cyclic voltammetry with platinum ultramicroelectrodes, absorption and fluorescence optical spectroscopies, the resulting integrated charge being indicative of a two electron process. The cyclic voltammograms registered for low scan speeds are characterized by a single irreversible diffusion controlled anodic wave, the related cathodic wave being also observable for scan speeds higher than $1 \mathrm{~V} \mathrm{~s}^{-1}$. Oxidation reaction stoichiommetric parameters were obtained through Tafel slopes resulting in unitary reaction orders for DIP and $\mathrm{H}^{+}$.

Keywords: dipyridamole, anodic oxidation, cyclic voltammetry, aqueous acid solution

\section{Introduction}

Dipyridamole (DIP), 2,6-bis(diethanolamino)-4,8dipiperidino [5,4-d] pyrimidine, is a drug used for the treatment of cardiovascular diseases due to its vasodilating and antiplatelet properties 1 . Its structure (Figure 1) presents a stable hetero-aromatic double ring core which is responsible for the characteristic absorption and fluorescence of the compound. It has been recently reported that DIP also exhibits a potent biological antioxidant activity behaving as an inhibitor of lipid peroxidation initiated by iron (II) ions $^{2}$ or by thermolabile azo compounds ${ }^{3}$, acting by the classical chain breaking mechanism as observed for Vitamin E. In the opinion of the authors 2,3 this mechanism involves the transfer of a hydrogen atom to peroxyl radicals. However, Pedulli et. al. ${ }^{4}$ reported, mainly based in calculated thermodynamic data for the hydrogen energy

Presented at the XI Simpósio Brasileiro de Eletroquímica e Eletroanalítica, Maragogi - AL, Brazil, April 5-9, 1999. Guest editor: Luis Alberto Avaca. bonds in the molecule, that the antioxidant action of DIP must result from the direct electron transfer reaction.<smiles>OCCN(CCO)c1nc(N2CCCCC2)c2nc(N(CCO)CCO)nc(N3CCCCC3)c2n1</smiles>

Figure 1. Structure of dipyridamole (DIP).

In previous work ${ }^{5}$ the electrochemical oxidation of DIP in organic solvents acetonitrile and ethanol was studied by cyclic voltammetry with ultramicroelectrodes, electronic absorption, fluorescence emission, and ESR spectroscopies. 
Voltammograms at high and low scanning rates showed a similar behavior in these different solvents, being characterized by two almost reversible voltammetric waves, corresponding to two consecutive one-electron losses. The electro-oxidation by only one electron produces a stable cationic radical which is easily detected by ESR 5 .

Although various methods have been employed for the analytical determination of DIP, including spectrophotometry 6 , high-performance liquid chromatography ${ }^{7}$ and stripping voltammetry 8,9 , the study of the anodic oxidation reaction of DIP in acid media can be useful to bring a better understanding over the compound chemical structure and nature, opening, eventually, new analytical possibilities.

The main objective of this work is to establish the proper stoichiometry for the anodic oxidation of DIP in aqueous acid solutions in which the compound can be somewhat extensively dissolved, and as an attempt to elucidate the mechanism of that reaction. The study was carried out in diluted acid solutions using cyclic voltammetry in combination with controlled potential electrolysis and potential stepped polarization data to obtain Tafel curve that allows the determination of the reaction orders for DIP and $\mathrm{H}^{+}$.

\section{Experimental}

\section{Chemicals}

All reagents used in this work were of analytical grade from Aldrich (dipyridamole), or Merck (sulfuric acid, potassium sulfate and others). Water treated in a Milli-Q system (Millipore) was used to prepare the solutions. All chemicals were used without previous purification.

\section{Cyclic voltammetry}

Cyclic voltammograms were registered at conventional platinum disk electrode $(\phi=0,5 \mathrm{~mm})$ and alternatively by using platinum disk ultramicroelectrodes $(\phi=25 \mu \mathrm{m})$, being recorded with a polarographic analyzer EG\&G, PAR Model 174-A, coupled to a home made interface adapted to an IBM-PC that acts as a function generator using a twelve bits digital to analog converter and as a data acquisition system by means of a twelve bits analog to digital converter 10 . The computer interface is controlled by a properly developed Windows ${ }^{\circledR}$ compatible program which allows the execution of most conventional electrochemistry techniques and provides the necessary facilities for data treatment.

A conventional electrochemical cell containing a platinum wire counter electrode and an $\mathrm{Ag} / \mathrm{AgCl} \mathrm{s}_{\text {(sat) }}$ reference electrode was employed for the conventional working electrode application and a two electrode cell was used in case of the ultramicroelectrode.
Solutions of DIP from 0.5 up to $5.0 \times 10^{-3} \mathrm{~mol} \mathrm{~L}^{-1}$ and of $\mathrm{H}_{2} \mathrm{SO}_{4}$ from 5 up to $100 \times 10^{-3} \mathrm{~mol} \mathrm{~L}^{-1}$ at constant ionic strength $(\mu=0.3)$ adjusted by proper addition of $\mathrm{K}_{2} \mathrm{SO}_{4}$ were used. Dissolved oxygen was removed from the solutions prior to the measurements by bubbling nitrogen (SS grade) from White Martins S.A. for $5 \mathrm{~min}$. Electrode surface was cleaned before use by polishing in a wet cloth embedded with alumina powder $0.05 \mathrm{~mm}$ diameter emulsion.

\section{Stepped Polarization Curves}

Steady state current data in the potentiostatic polarization mode were taken by the application of a programmed potential staircase within the appropriate potential range for each experiment with a pre-programmed step duration of 3 seconds, the current being sampled at the end of each step.

\section{Controlled potential electrolysis}

Controlled potential electrolysis experiments were performed for DIP $0.5 \times 10^{-3} \mathrm{~mol} \mathrm{~L}^{-1}$ containing $0.1 \mathrm{~mol} \mathrm{~L}^{-1}$ acetate buffer $(\mathrm{pH}=3.0)$ using a two compartment electrolysis cell supplied with a $4.2 \mathrm{~cm}^{2}$ area platinum foil working electrode and a larger auxiliary platinum electrode positioned in the other cell compartment. The same reference electrode as described above was used in the electrolytic cell. The progress of the electrolysis was monitored every 15 minutes by cyclic voltammetric experiments with platinum disk ultramicroelectrode, and by registering the optical absorption and fluorescence emission spectra. The electrolysis potential was kept applied for 60 min until no more current flow was observed, a negligible residual current being registered in pre-electrolysis experiments. Optical absorption spectra were obtained in a HITACHI U2000 spectrophotometer coupled to a IBM-PC with the Spectracalc software (Galactic). Fluorescence spectra were obtained in a JASCO FP-777 spectrofluorimeter using quartz cuvettes (Hellma) of $1 \mathrm{~mm}$ optical path oriented at $45^{\circ}$ with relation to the excitation beam. The sample was excited at $415 \mathrm{~nm}$ and the emission spectra was recorded in the range $425-600 \mathrm{~nm}$. All measurements were carried out at laboratory ambient temperature controlled at $25 \pm 2 \mathrm{oC}$.

\section{Results and Discussion}

\section{Voltammetric measurements with conventional and ultramicroelectrodes}

As shown in Figure 2, at low scan speeds the voltammetric curves registered for DIP $1.0 \times 10^{-3} \mathrm{~mol} \mathrm{~L}^{-1}$ in $0.10 \mathrm{~mol} \mathrm{~L}^{-1}$ $\mathrm{H}_{2} \mathrm{SO}_{4}$ solutions presents the typical behavior of irreversible diffusion controlled voltammograms, while for scan speed values higher than $1 \mathrm{~V} \mathrm{~s}^{-1}$ the corresponding cathodic peak 
became visible which is indicative of electrolysis product consumption by a slower homogeneous chemical reaction that follows the electron transfer step. The voltammetric parameters measured over the range of scan speeds investigated are presented in Table 1, where the listed values for $\mathrm{E}_{\mathrm{p}}-\mathrm{E}_{\mathrm{p} / 2}$ are that expected for a two electrode process. The slight increase observed for $E_{p}-E_{p / 2}$ for high scan speeds is indicative of some quasi-irreversibility of the electrode reaction. Figure 3 presents the variation of $\mathrm{I}_{\mathrm{pa}}$ as a function of $\mathrm{v}^{1 / 2}$ where it can be seen that there is a diffusion limited process for low scan speeds that became kinetically controlled in the region of higher scan speeds.

Table 1. Electrochemical parameters obtained by voltammetric oxidation of DIP $1.0 \times 10^{-3} \mathrm{~mol} \mathrm{~L}^{-1}$ in $\mathrm{H}_{2} \mathrm{SO}_{4}$ solution $0.1 \mathrm{~mol} \mathrm{~L}^{-1}$, platinum electrode $\phi=0.5 \mathrm{~mm}$.

\begin{tabular}{cccccc}
\hline $\begin{array}{c}v \\
\left(\mathrm{Vs}^{-1}\right)\end{array}$ & $\begin{array}{c}\mathrm{E}_{\mathrm{pa}} \\
(\mathrm{mV})\end{array}$ & $\begin{array}{c}\mathrm{i}_{\mathrm{pa}} \\
(\mu \mathrm{A})\end{array}$ & $\begin{array}{c}\mathrm{E}_{\mathrm{pc}} \\
(\mathrm{mV})\end{array}$ & $\begin{array}{c}\mathrm{I}_{\mathrm{pa}} / \mathrm{v}^{1 / 2} \\
\left(\mu \mathrm{A} \cdot \mathrm{mV}^{-1 / 2} \mathrm{~s}^{1 / 2}\right)\end{array}$ & $\begin{array}{c}\mathrm{E}_{\mathrm{p}}-\mathrm{E}_{\mathrm{p} / 2} \\
(\mathrm{mV})\end{array}$ \\
\hline 0.002 & 609 & 0.23 & - & 0.16 & 31 \\
0.010 & 618 & 0.43 & - & 0.13 & 33 \\
0.050 & 627 & 0.84 & - & 0.12 & 33 \\
0.10 & 631 & 1.12 & - & 0.11 & 34 \\
1.0 & 638 & 2.92 & - & 0.09 & 37 \\
2.0 & 649 & 3.86 & 586 & 0.08 & 42 \\
6.0 & 658 & 4.7 & 580 & 0.06 & 48 \\
10.0 & 660 & 5.12 & 580 & 0.05 & 46 \\
\hline
\end{tabular}

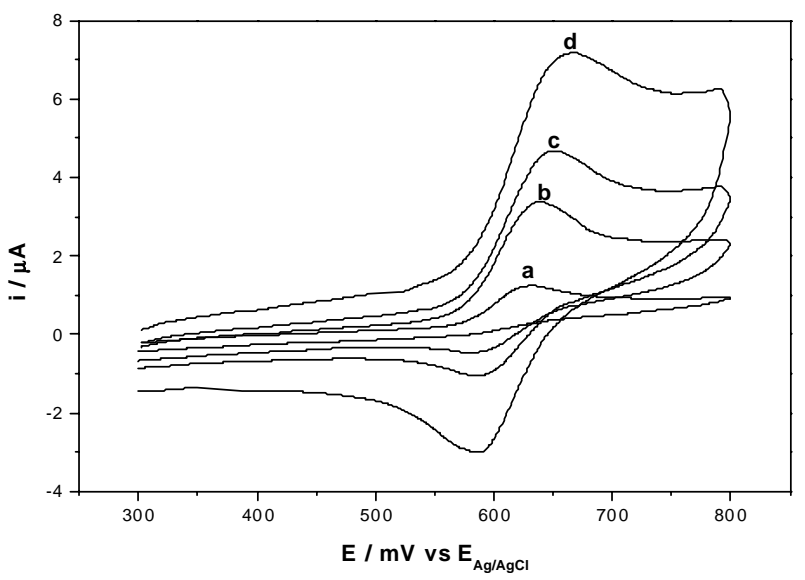

Figure 2. Cyclic voltammograms for DIP $1.0 \times 10^{-3} \mathrm{~mol} \mathrm{~L}^{-1}$ at $\mathrm{Pt}$ disk electrode $(\phi=0.5 \mathrm{~mm})$ in $0.1 \mathrm{~mol} \mathrm{~L}^{-1} \mathrm{H}_{2} \mathrm{SO}_{4}$ solution. $v$ (a) 0.1 ; (b) 1.0 ; (c) 2.0 ; (d) $10.0 \mathrm{Vs}^{-1}$.

The behavior of the current function $\left(\mathrm{I}_{\mathrm{p}} \mathrm{v}^{-1 / 2}\right)$ which decreases exponentially as the scan speed increases (Figure 4) is also compatible with an electrode reaction coupled with a following chemical reaction (ECi), as is the increase in the value of the anodic peak potential $\left(\mathrm{E}_{\mathrm{pa}}\right)$ observed with the increase in scan speed (Table 1). Voltammetric anodic peak currents registered at $\mathrm{v}=10 \mathrm{mV}$ $\mathrm{s}^{-1}$ in the 0.5 to $5 \times 10^{-3} \mathrm{~mol} \mathrm{~L}^{-1}$ DIP concentration range showed good linearity (correlation coefficient $r=0.997$ ), as expected for a diffusion controlled process.

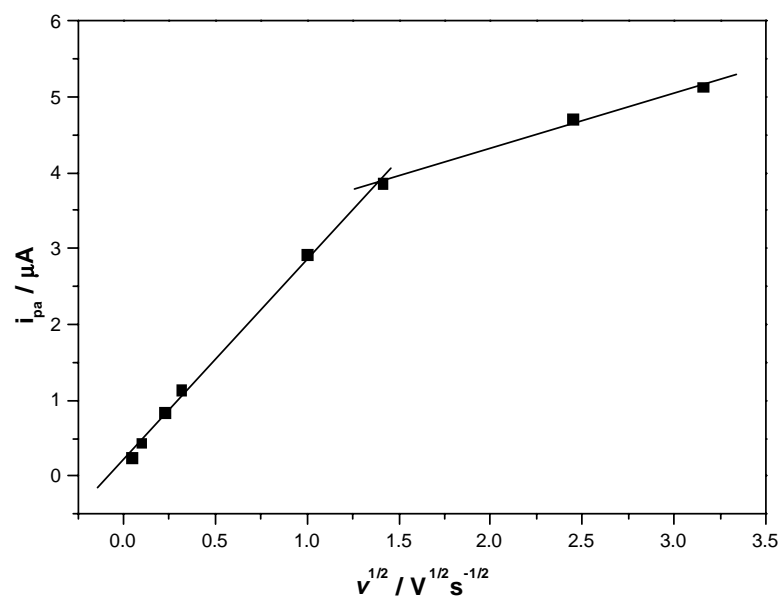

Figure 3. Anodic peak currents $\left(i_{p a}\right.$ ) for DIP as a function of $v^{1 / 2}$, obtained in $1.0 \times 10^{-3} \mathrm{~mol} \mathrm{~L}^{-1}$ of DIP in $0.1 \mathrm{~mol} \mathrm{~L}^{-1} \mathrm{H}_{2} \mathrm{SO}_{4}$ solution at the Pt disk electrode $(\phi=0.5 \mathrm{~mm}) . \mathrm{r}=0.9986$.

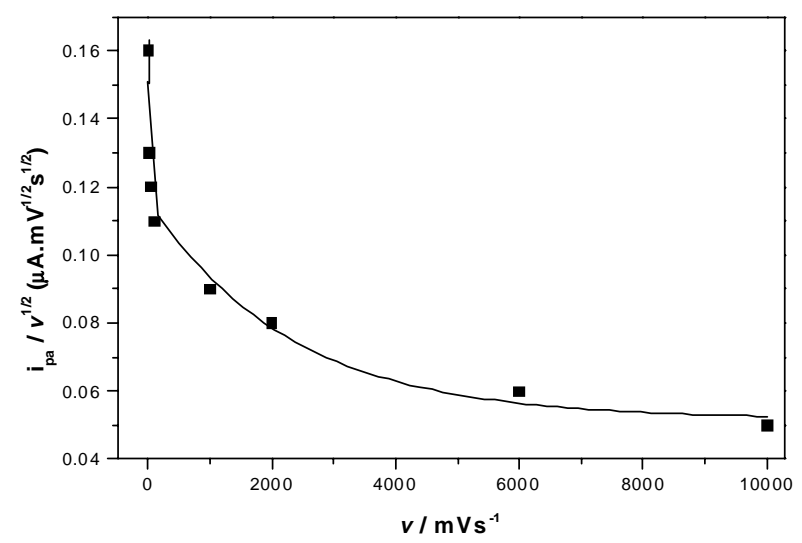

Figure 4. Variation of the current function $\left(\mathrm{i}_{\mathrm{pa}} / \mathrm{v}^{1 / 2}\right)$ with scan rate for DIP $1.0 \times 10^{-3} \mathrm{~mol} \mathrm{~L}^{-1}$ in $0,1 \mathrm{~mol} \mathrm{~L}^{-1} \mathrm{H}_{2} \mathrm{SO}_{4}$.

Cyclic voltammetric curves obtained with the platinum disk ultramicroelectrode are shown in Figure $5 \mathrm{~A}$, while Figure 5 B presents a cyclic voltammogram for a $1.0 \times 10^{-3}$ mol L-1 potassium ferricyanide solution registered in the same conditions. The half-wave potentials for the ongoing voltammetries were calculated by the log-plot procedure being $0.598 \mathrm{~V}$ for DIP and $0.343 \mathrm{~V}$ for the ferricyanide vs. $\mathrm{Ag} / \mathrm{AgCl}_{\text {(sat) }}$ electrode, with the respective values of 44 and $62 \mathrm{mV} /$ decade obtained from the Log-plot slopes. The precise site of protonation of DIP is still unknown. The fluorescence emission of DIP decreases sharply with the acidification of the medium showing a single $\mathrm{pK}_{\mathrm{a}}$ of 5.8 in aqueous solution. In the case of a dipyridamole derivative, RA25, which has the same substituents in all positions of the pyrimido pyrimidine ring (methylamines at positions 2,6,4,8), two $\mathrm{pK}_{\mathrm{a}}$ values of 5.2 and 2.2 were observed in fluorescence emission titration ${ }^{11}$. Comparison with $\mathrm{pK}_{\mathrm{a}}$ values of simple similar compounds suggests that the unique $\mathrm{pK}_{\mathrm{a}}$ of 5.8 for DIP is due to protonation of the nitrogens of 
both substituents, bis-ethanolamines and piperidines. The $\mathrm{pK}_{\mathrm{a}}$ of the nitrogens of the pyrimido pyrimidine ring are probably quite low (below 2) and the formation of an intramolecular hydrogen bond of these nitrogens to the bisethanolamine substituents would make it even lower, unobservable. In the case of RA25 the observation of two $\mathrm{pK}_{\mathrm{a}}$ values is probably associated to both protonation of the methylamine nitrogens $\left(\mathrm{pK}_{\mathrm{a}}=5.2\right)$ and the nitrogens in the ring $\left(\mathrm{pK}_{\mathrm{a}}=2.2\right)$. In this case the impossibility of intramolecular bond formation would allow the observation of this second $\mathrm{pK}_{\mathrm{a}}$ due to the protonation of the ring nitrogens, not observed in DIP. Considering, in agreement with the $\mathrm{pKa}$ value of DIP of 5.8 previously measured by spectroscopy 12,13 , that the DIP is totally protonated in the $0.1 \mathrm{~mol}$ $\mathrm{L}^{-1} \mathrm{H}_{2} \mathrm{SO}_{4}$ solutions, and by comparison with the oxidative potentials of other known antioxidants like ascorbic acid, it is possible to preview that DIP can still act as an antioxidant when protonated. Otherwise it can be stated, based on the measured diffusion limited current, that the protonated DIP is 2.6 times less mobile than the ferricyanide ion in this medium.

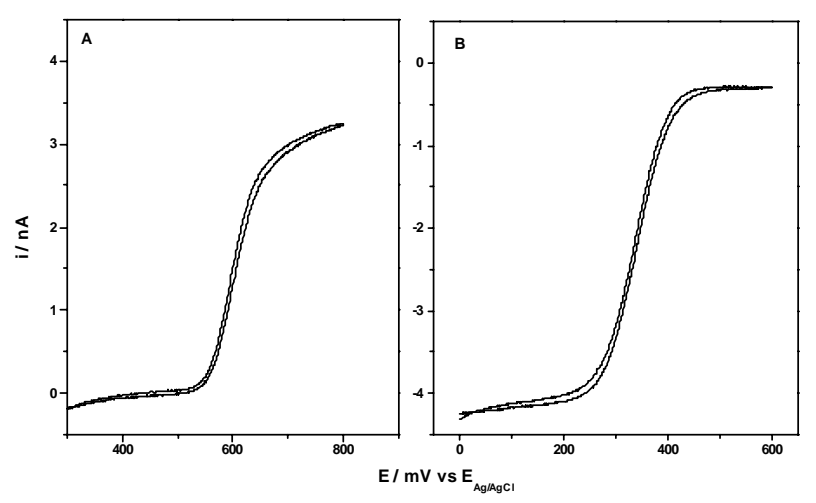

Figure 5. Cyclic voltammograms of (A) $1.0 \times 10^{-3} \mathrm{~mol} \mathrm{~L}^{-1} \mathrm{DIP}$ and (B) $1.0 \times 10^{-3} \mathrm{~mol} \mathrm{~L}^{-1} \mathrm{~K}_{3} \mathrm{Fe}(\mathrm{CN})_{6}$ in $0.1 \mathrm{~mol} \mathrm{~L}^{-1} \mathrm{H}_{2} \mathrm{SO}_{4}$ solutions at Pt UME $(\phi=25 \mathrm{~mm}) \mathrm{v}=2 \mathrm{mVs}^{-1}$.

\section{Current-potential diagrams}

The stepped polarization procedure as described above provides current data values that can be related to the quasistationary condition and that can be used to construct Tafel lines by plotting $\log \mathrm{i}$ vs $\mathrm{E}$, as show in Figure 6 for different DIP concentrations and in Figure 7 for different sulfuric acid concentrations. The analysis of the slopes of Tafel plots for the two cases shows linear segments with slopes close to $30 \mathrm{mV} /$ decade as expected for a two electron reaction.

The $\log \mathrm{i}$ vs $\log \mathrm{C}_{\text {DIP }}$ curve plotted in the insert for Figure 6, obtained for currents at the fixed E value of +570 $\mathrm{mV}$ results in a straight line with a slope of 0.98 and correlation coefficient $r=0.999$, which implies in the participation of only one DIP molecule in the electrode process excluding the occurrence of other competing reaction. The same procedure applied to the data presented in Figure 7 results in the plot of $\log \mathrm{i}$ vs $\log \mathrm{C}_{\mathrm{H}+}$ shown in the insert for that figure where the obtained straight line has a slope of -1.15 which is indicative of the release of one $\mathrm{H}^{+}$ion for each oxidized DIP molecule.

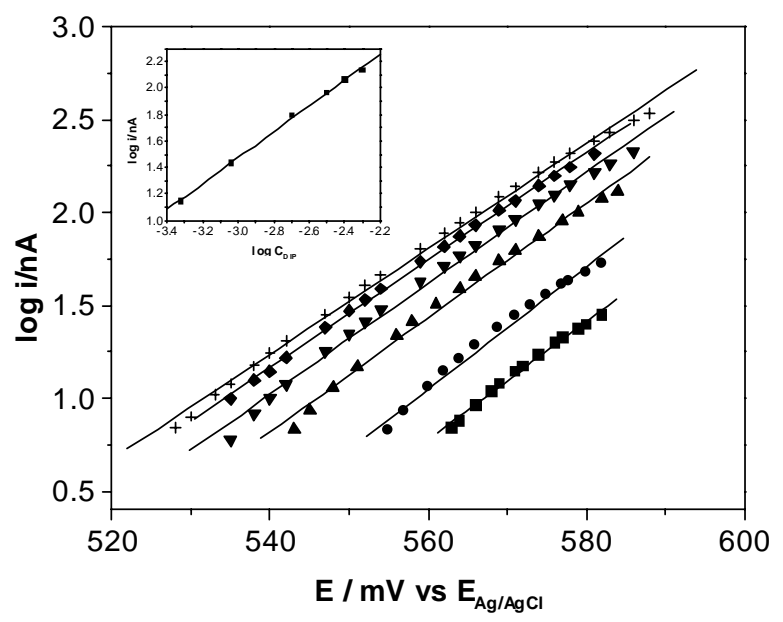

Figure 6. Tafel plots for different concentrations of DIP in

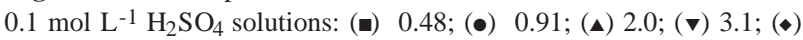
3.94 and (+) $5.0 \times 10^{-3} \mathrm{~mol} \mathrm{~L}^{-1}$. Insert $-\log \mathrm{i} / \mathrm{nA}$ vs. $\log \mathrm{C}_{\text {DIP }}$ in 0.1 mol L-1 $\mathrm{H}_{2} \mathrm{SO}_{4}, \mathrm{E}=+570 \mathrm{mV}$. $\mathrm{r}=0.999$

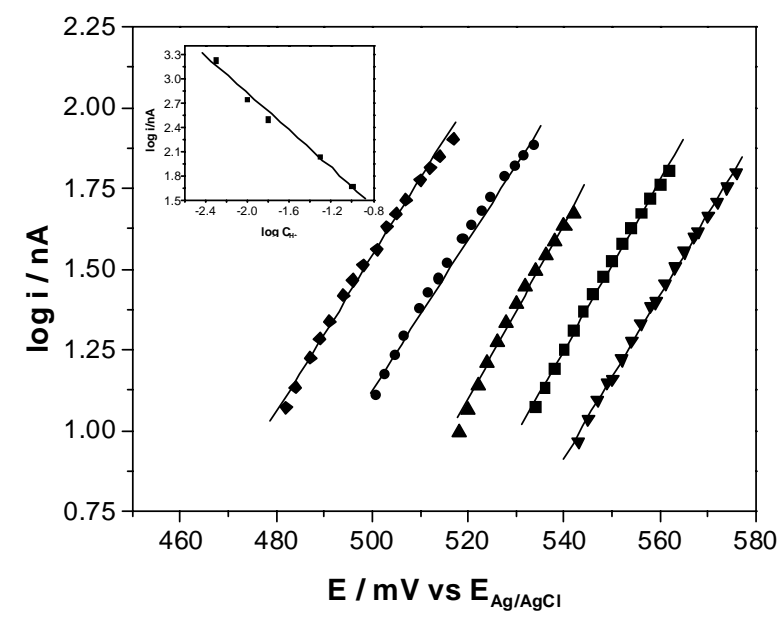

Figure 7. Tafel plots for different concentrations of $\mathrm{H}_{2} \mathrm{SO}_{4}(\bullet) 5.0$;

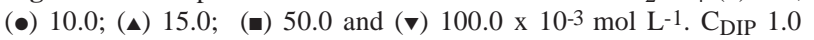
x 10-3 mol L-1. Insert - Log i / nA vs. $\log \mathrm{C}_{\mathrm{H}^{+}}, \mathrm{E}=+570 \mathrm{mV}, \mathrm{r}=0.996$.

\section{Controlledpotential electrolysis}

Exhaustive electrolysis experiments were conducted to confirm the number of electrons involved, the reaction completion and the possibility to prepare the electrolytic products for subsequent identification. These experiments were monitored by recording cyclic voltammetry with 
ultramicroelectrode at low scan speed, where a progressive decay in the diffusion current was observed, showing the total consumption of DIP after 60 minutes of the electrolysis process (Figure 8). The integrated electrolysis charge was also that expected for the two electron removal of each DIP molecule.

The optical absorption spectra were also registered every 15 minutes during the course of the electrolysis and, as shown in Figure 9, the absorption band with maximum close to $400 \mathrm{~nm}$ disappears while the ultra violet band at $280 \mathrm{~nm}$ decreases in intensity shifting to shorter wavelength values. This new spectrum of the discolored solution can be attributed to the presence of the oxidation products for this reaction.

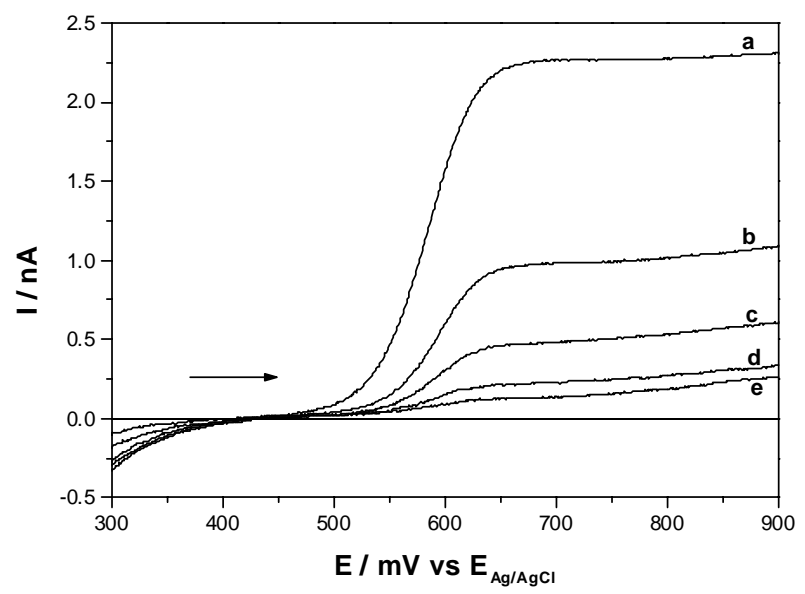

Figure 8. Cyclic voltammograms (forward scans) for the oxidation of $0.5 \times 10^{-3} \mathrm{~mol} \mathrm{~L}^{-1}$ of DIP in $0.1 \mathrm{~mol} \mathrm{~L}^{-1}$ acetate buffer solution $(\mathrm{pH}=3.0)$, at UME of $\mathrm{Pt}(\phi=25 \mathrm{~mm}), \mathrm{v}=20 \mathrm{mV} \mathrm{s}^{-1}$. Bulk electrolysis at $\mathrm{E}=+850 \mathrm{mV}$ (a) 0 ; (b) 15 ; (c) 30; (d) 45 and (e) $60 \mathrm{~min}$.

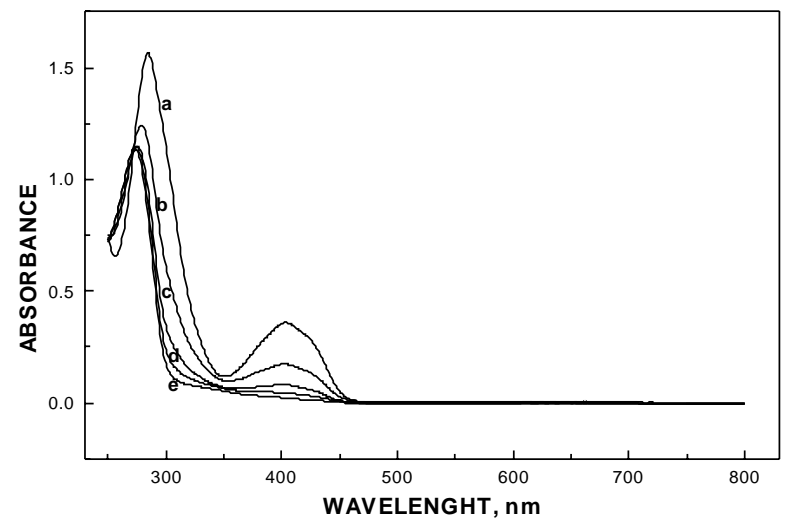

Figure 9. Optical absorption spectra of DIP $0.5 \times 10^{-3} \mathrm{~mol} \mathrm{~L}^{-1}$ in $0.1 \mathrm{~mol} \mathrm{~L}^{-1}$ acetate buffer solution ( $\left.\mathrm{pH}=3.0\right)$, during bulk electrolysis at $\mathrm{E}=+850 \mathrm{mV}$ : (a) 0; (b) 15; (c) 30; (d) 45 and (e) $60 \mathrm{~min}$.

The fluorescence emission spectra were also registered. Before the electrolysis the starting fluorescence emission with maximum at $500 \mathrm{~nm}$ has an intensity which was found to be $3 \%$ of the value found in acetonitrile solvent. Due to the protonation the fluorescence of DIP is significantly reduced 12,13 . The fluorescence emission vanishes completely in the course of the electrolysis.

\section{Reaction stoichiometryforDIP oxidation}

According to the results of the present work the equation for the electrochemical heterogeneous irreversible oxidation reaction of dipyridamole in acid media can be written as:

$$
\mathrm{DIPH}^{+} \rightarrow \mathrm{A}^{2+}+\mathrm{H}^{+}+2 \mathrm{e}^{-}
$$

$\mathrm{A}^{2+}$ is the resulting product from the electrochemical reaction, which is chemically consumed probably by one homogeneous hydrolytic reaction.

It is worth of mention that in the analytical determination of DIP in acidic medium in the presence of $\mathrm{H}_{2} \mathrm{O}_{2}$ the authors suggested that the cleavage of the piperidine ring with the formation of an aldehyde occurs as a first step with the subsequent formation of an $\mathrm{N}$-oxide derivative in the pyrimido pyrimidine ring 14 . Since they did not characterize the final oxidation product (s) this proposal remains only speculative.

The observed mechanism is in contrast with the oxidation process observed in organic solvents like acetonitrile where a two step one electron process was found, the first one corresponding to the formation of a stable cationic radical. In that non-aqueous medium the second process leads to a larger number of oxidation products which are observed by analysis of the optical and voltammetric spectra. Besides that the cationic radical is not stabilized in aqueous acidic solutions which is consistent with the fact that DIP protonation makes the oxidation more difficult increasing the necessary potential corresponding to a two-electron process.

Additional relevant mechanistic conclusions can only be drawn by the proper study of the molecule electronic structure, and by the identification of the reaction products in the different media. Some analytical studies with these purposes are in course.

\section{Conclusions}

The electrochemical oxidation of DIP in aqueous acid medium is characterized by an irreversible two electron process where the primary oxidation product is transformed by a coupled homogeneous irreversible reaction. The observed voltammetric behavior is compatible with an ECi overall reaction mechanism, which will be object of future research. The voltammetric experiments carried out at high scan speeds (above $1 \mathrm{~V} \mathrm{~s}^{-1}$ ) 
show the appearance of the reduction process, which means that the chemically coupled reaction is not very fast and can be followed by voltammetry. Repetitive cyclic voltammetric experiments have shown that the electrode reaction is clean in the sense that the electrode remains activated after a great number of cycles.

Despite the characteristic symmetric double functionality of the DIP structure the stoichiommetry found for the anodic oxidation of DIP in aqueous acid solutions corresponds to a two electrons removal for each DIP molecule followed by the release of one proton per oxidized molecule.

These conclusions were supported by the application of the usually accepted criteria for mechanistic choice based on Tafel data.

\section{Acknowledgments}

The authors are grateful to FAPESP, CNPq, CAPES and FINEP for financial support.

\section{References}

1. Fitzgerald, G. A. N. Engl. J. Med. 1987, 316, 1247.
2. De La Cruz, J. P.; Carrasco, T.; Ortega, G.; Sánches de la Cuesta, F. Lipids 1992, 27, 192.

3. Iuliano, L.; Pedersen, J. Z.; Rotilio, G.; Ferro, D.; Violi, F. Free Rad. Biol. Med. 1995, 18, 239.

4. Pedulli, G. F.; Lucarini, M.; Marchesi, E.; Paolucci, F.; Roffia, S.; Fiorentini, D.; Landi, L. Free Rad. Biol. Med. 1999, 26, 295.

5. Almeida, L. E.; Castilho, M.; Mazo, L. H.; Tabak, M. Anal. Chim. Acta 1998, 375, 223.

6. Barary, M. H.; El-Sayed, M. A. H.;Abdel-Hay, M. H.; Mohamed, S. M. Anal. Lett. 1989, 22(7), 1643.

7. Zhang, J.; Miller, R. B.; Russel, S.; Jacobus, R. J. Liq. Chrom. \& Rel. Technol. 1997, 20(13), 2109.

8. Zeng, X.; Lin, S.; Hu, N. Talanta 1993, 40, 1183.

9. Wang, Z.; Zhang, H.; Zhou, S. Talanta 1997, 44, 621.

10. Mazo, L. H.; Machado, S. A. S.; Avaca, L.A. Instrum. Scienc. Technol. 1994, 22, 61.

11. Borges, C. P. F.; Tabak, M. Spectrochimica Acta 1994 $50 A(6), 1047$.

12. Borissevitch, I. E.; Tabak, M. J. of Luminescence 1992, 51, 315.

13. Borges, C. P. F.; Borissevitch, I. E.; Tabak, M. J. of Luminescence 1995, 65, 105.

Received: June 01, 1999

FAPESP helped in meeting the publication costs of this article. 